\title{
Obituary
}

\section{Sir Erik Christopher Zeeman FRS 1925-2016}

Christopher Zeeman was born in Japan on 4 February 1925 to a Danish father, Christian, and British mother, Christine. When he was one year old, his parents moved to England. He was a pupil at the independent school Christ's Hospital, in Horsham, West Sussex. Between 1943 and 1947 he was a flying officer in the Royal Air Force. In a career change that was to have major impact on British mathematics, he studied the subject at Christ's College, Cambridge University, graduating with an MA degree. He then carried out research for a $\mathrm{PhD}$ at Cambridge, supervised by the topologist Shaun Wylie.

His topic was an area of algebraic topology, which associates abstract algebraic structures ('invariants') to topological spaces in such a way that continuous maps between spaces induce structure-preserving maps between the corresponding algebraic structures. In this manner, questions about topology can be reduced to more tractable questions in algebra. His thesis combined two such invariants, homology and cohomology, which go back to the seminal work of Henri Poincare at the start of the 20th century.* The result was named dihomology. He introduced an important technical tool to extract useful information from this set-up, now known as the Zeeman spectral sequence. His work led Robert MacPherson and Mark Goresky to invent the basic notion of intersection homology; these ideas in turn led to proofs of some major conjectures, including the Kazhdan-Lusztig conjectures in group representation theory and the Riemann-Hilbert correspondence for complex differential equations.

Christopher concentrated on difficult problems. He answered a longstanding question about unknotting spheres in five-dimensional space [1], and proved the engulfing theorem, which led to a proof of the Poincaré conjecture for spaces of dimension 5 or higher [2]. John Stallings independently proved the same results [3]. The Poincaré conjecture characterises high-dimensional analogues of the sphere in terms of simple topological properties. Around 1900 Poincare claimed that any threedimensional manifold (a special type of topological space) with the same homology groups as a 3-dimensional sphere must in fact be topologically equivalent to a 3-dimensional sphere. In 1904 he published a counterexample, constructed by gluing two tori together, using a new invariant known as the fundamental group (the first example of what is now called a homotopy group) to distinguish this space from the 3-dimensional sphere.

To avoid lengthy digressions, most technical terms used in this obituary will not be explained. They can be found on the internet or elsewhere. 
The Poincaré conjecture proved intractable, so topologists attempted to solve it by generalising the statement to spheres of any dimension. By 2000, the conjecture had been proved for every dimension except 3 - the dimension to which Poincaré's original conjecture applies. A complete proof was obtained by Grigori Perelman in 2003 using new methods related to curvature.

In the early 1960s Christopher moved to Warwick with the express intention of setting up an international centre specialising in mathematical research. Today there are many of these, but back then the main ones were the Mathematisches Forschungsinstitut Oberwolfach in Germany, founded in 1944, the Instituto Nacional de Matemática Pura e Aplicada (Rio de Janeiro 1952), and the Institut des Hautes Études Scientifiques (Bures-surYvette, near Paris, 1958). The Science Research Council of the UK had expressed interest in funding a British centre along similar lines. Christopher once told me that Cambridge had been invited to bid and declined; this was the main reason he decided to up sticks to pastures new, seeking a more imaginative university willing to host it. Warwick certainly had pastures it was mostly open fields, with a few buildings rising from a sea of mud and as the new kid on the block it was open to novel ideas.

And so Warwick acquired Christopher, its Mathematics Research Centre, and its Mathematics Department. Jointly these two operations which administratively were separate entities — formed the Mathematics Institute. Initially, Christopher ran them both. But from the beginning he knew that as they grew, they would become too big for one person to run, so he set everything up so that it was clear which hat he was wearing for which decision. He began by making fifteen appointments in what he referred to as the 'three pillars of modern mathematics': algebra, analysis, and topology. He believed that the best way to encourage top-quality research was to begin with specialist groups in important areas, whose members would interact with each other to achieve critical mass. Diversity would come later, building on those strengths. Initially he invited several key figures to join him. According to a persistent legend, they all declined, so he wrote to each of them saying 'that's a pity, the others have all accepted'. Christopher never denied this, and at least one of those concerned confirmed it to me. He was seldom devious, but he was adaptable if the occasion demanded it.

The Mathematics Research Centre started with a bang, by hosting a series of annual Symposia: year-long special programmes in hot topics that attracted hundreds of the world's top mathematicians. Stephen Smale, Jack Milnor, Bill Thurston, John Thompson, Michael Artin, Richard Brauer, Vladimir Arnold... they all passed through Warwick very early on. And they kept coming. The list of visitors was like a Who's Who of mathematics. All part of Christopher's grand (and successful) scheme to make Warwick a household name in world mathematics.

In accordance with this scheme, he got involved in the subject at all levels, from primary school teaching to the Royal Society. He was a brilliant public speaker, and he was very active in public engagement at a time when 
this was almost unheard of for an academic: talking to schools, giving public lectures, appearing on the radio. Soon after I arrived at Warwick in 1967 as a $\mathrm{PhD}$ student, he appeared on the radio (BBC Third Programme ) talking on 'Topology in the Scientist's Toolkit'. As a result, Warwick never developed the attitude that such things were beneath the attention of serious academics - as long as you performed all your main teaching, research, and administrative duties to the full too. Christopher played a huge role in encouraging my own outreach activities; I think he detected a fellow spirit.

The Mathematics Institute first set up shop in a house on Kenilworth Road, Coventry, but quickly moved to another larger house, where Stoneleigh Road intersected Kenilworth Road and became Gibbet Hill Road. This auspicious name reflects the time-honoured habit of hanging criminals at crossroads to maximise exposure, a practice that is now, mercifully, long gone. The Department also had extra offices for staff and postgraduates in what had been the University Library on what we then called the East Site (now Gibbet Hill Campus). (When Warwick was founded it started with a 40-acre site for a small College, but founding Vice Chancellor Jack Butterworth had greater ambitions and rapidly expanded by a further 400 acres just down the road.)

Christopher's office was just off the corridor leading to the kitchen, the source of coffee in the morning and tea in the afternoon, a cunning ploy to lure staff and graduate students over to the Institute to talk to each other. There were wall-to-wall seminars - we had so many visitors - and a weekly colloquium. When the Department grew, it decamped to Gibbet Hill, with a major conversion of the old library. The students had been playing badminton there; now the area became two lecture rooms. Where we had played table tennis was now the new common room, with a large library adjacent to it. Christopher planned the entire conversion himself.

Christopher had immense presence. The beard definitely helped. He was good-looking, mostly genial but with a backbone of steel, and you knew it wouldn't be a good idea to make him angry. He worked all the hours God gave, and would happily have worked more if it had been possible. He kept an eye on everything, aided and abetted by a growing coterie of professors, readers, and lecturers. When a group of postgraduates and undergraduates wanted to start a mathematics fanzine, he gave us access to duplicating equipment and paper. (No wordprocessors then; no computers - the university had a Burroughs mainframe programmed with punched cards. State of the art. Somewhere in the administration building was a xerox machine. We duplicated handwritten examples sheets on a Banda.) Eventually the fanzine, named Manifold [4], got to twenty issues, with a circulation that peaked at 650 .

Traditionally, UK mathematics had long been divided into 'pure' and 'applied', and divided was the word. Read G. H. Hardy's otherwise elegant and informative A Mathematician's Apology for the (hopelessly narrow) mind-set. A more accurate description of the subject sees it as a continuous spectrum between these extremes. Christopher always considered applied 
mathematics to be just as important as pure mathematics, but he was unimpressed by the rather cavalier attitude to mathematical structure which was prevalent in academic applied mathematics at that time. (To be fair to Hardy, that was one reason he preferred pure mathematics.)

In Warwick's early days, applied mathematics was mainly the concern of the Departments that applied it, such as Physics and Engineering. So most staff in the Department were pure mathematicians. Over the years, the University's attitude to applied mathematics changed and the Mathematics Department hired applied mathematicians too. For decades the Department fought a lengthy rear-guard action to convince the powers that be to consider Warwick as a single Mathematics Department in which there was no hard and fast pure/applied boundary. Eventually, as a result of assessment exercises introduced by the Thatcher government, staff were forced to shoehorn themselves into one or other category for administrative purposes. The Mathematics Department remains a single integrated whole in all other respects, in accordance with Christopher's initial vision. It also belongs to five spin-off specialist research centres. The expansion into applied mathematics proved so successful that in one rating exercise applied outperformed pure.

Christopher took a special interest in mathematical biology — a subject which, in the 1960s, hardly existed. Biology and Mathematics Departments didn't so much see eye to eye as eyeball to eyeball. In the heady days of the great discoveries in molecular biology, most biologists were hostile to any suggestion that mathematics could help them understand the living world (apart from statistics to put p-values on their experimental data, Bragg's law in X-ray diffraction, and the Hodgkin-Huxley equations for transmission of nerve impulses). Biology was also the area of science into which people who didn't want to do mathematics naturally gravitated. Today that attitude is rapidly disappearing, and Christopher was one of the pioneers who helped bring it about.

I remember Christopher saying that there were two types of mathematician (he tended to talk in black and white, though his thinking was subtler): those who stay in one area and learn new techniques as they become necessary, and those who like a particular way of thinking and follow it into whichever hot area is currently using it. He was of the second kind; he loved geometry — not just Euclid, but all forms of thinking based on visual intuition, especially topology — and the 1970s gave him the opportunity to use his beloved geometry to make progress in biology and other applied areas. Around 1970 the French topologist René Thom was promoting what he called a 'theory of models', a kind of top-down approach to mathematical models of reality. The idea was to find out which features of models are common to many different types of equation, rather than being special features of just one type. Thom felt this was especially important in biology, where accurate models along the lines of Newton's law of gravity were not available. In short, since biologists didn't know the exact equations, deductions based on any specific choice were questionable. 
This idea led Thom to a wonderfully rich geometric structure, a list of 'catastrophes élémentaires' - a topological classification of sudden changes. Christopher promptly put aside all other research problems to concentrate on what the media quickly dubbed 'catastrophe theory'. He gave the world's first lecture course on the topic, and interacted with scientists from any areas - biology, physics, economics, statistics, even sociology [5]. The unusual level of media attention (for those days - nowadays it wouldn't raise an eyebrow) led some to denounce 'catastrophe theory' as hype. However, the critics mostly took the dumbed-down media version of the theory as the literal truth, and ignored the technical subject behind it. Catastrophe theory, now renamed singularity theory, has become an important technique in many applied areas. One of Christopher's early proposals - denounced along with everything else — was a 'clock and wavefront' model of a key stage in the development of a vertebrate. It was recently shown to be correct [6]. He was a visionary, ahead of his time.

Christopher's greatest media achievement was to deliver the 1978 Royal Institution Christmas Lectures on BBC television. In 1825 Michael Faraday decided that a good way to enthuse young people about science was to set up a short series of popular lectures at Christmas, with lots of demonstrations (especially loud bangs) explaining important scientific ideas. Mathematics was almost invisible early on, although in 1936 Geoffrey Ingram Taylor gave lectures on the dynamics of ships - and, remarkably, it now turns out that the BBC televised one, thirty years before what everyone thought had been the first televised series, and only two weeks after the start of regular transmissions. (Ship stability happens to be a beautiful application of catastrophe theory, as Christopher discovered.) He was the first pure mathematician to give the lectures, talking on topics including boomerangs and gyroscopes, perspective drawing in art, and - of course - catastrophe theory.

He received innumerable academic honours. He was elected a Fellow of the Royal Society in 1975, and was President of the London Mathematical Society, the UK's major pure mathematical professional body, from 198688. In 1988 he was awarded the Royal Society's Michael Faraday prize, a prestigious award for promoting the public understanding of science. From 1988 to 1994 he was Professor of Geometry at Gresham College, giving twelve free public lectures a year. The Institute of Mathematics and its Applications and the London Mathematical Society jointly set up the Zeeman Medal in his honour, for activities in public awareness of mathematics. In 1988 he left Warwick University to become Principal of Hertford College, Oxford, largely because at that time there was a mandatory retirement age at Warwick of 67, whereas at Oxford it was 70.

In 1991 he was knighted for 'mathematical excellence and service to British mathematics and mathematics education'. The Institute of Mathematics and Its Applications and the London Mathematical Society jointly set up the Zeeman medal in his honour, for activities in public awareness of mathematics. In 2015 large gathering of family, friends, and 
colleagues celebrated his 90th birthday at Hertford College, a memorable and poignant occasion.

In 1978 Tim Poston (one of Christopher's PhD students) and I summed up our feelings about his influence in a haiku, as a dedication for our 1978 research text Catastrophe Theory and its Applications [7] based on his lecture course and subsequent developments:

to Christopher Zeeman

at whose feet we sit

on whose shoulders we stand

It remains a powerful and accurate statement about his energy, zeal, taste, diversity, and influence on world mathematics.

Christopher's greatest tangible memorial is the Warwick Mathematics Institute, now housed in the Zeeman Building. Under his leadership as founding Professor and Director of the Mathematics Research Centre, and with the enthusiastic assistance of his staff, this fledgling operation grew rapidly into a major world research centre. It has gone from strength to strength ever since. Barely 50 years old, Warwick is now among the UK's top six mathematics departments, and its degree programme was recently assessed as number 13 in the world. Christopher played a central role in making the Institute what it is today.

Given the amazing range of his activities it is extraordinary that Christopher was involved with The Mathematical Association. But he was. His first item in the Gazette was called On the relation between real Euclidean and complex projective geometry [8]. His vigour seemed never to wane. In 2002, the Association invited him to be its President for the year 2003 to 2004 an invitation which he accepted with typical enthusiasm. He regularly attended meetings of Council and provided a splendid Presidential Address at the York conference in 2004. This resulted in a 96-page supplement to the Gazette, rather than perhaps a 15 page Article in the Gazette itself and was converted into a book Three-dimsional theorems for Schools, [9].

In 2005 the Association added him to its list of Honorary Members.

He is survived by his second wife, Rosemary (née Gledhill), their sons Tristan, Crispin and Sam, and daughters Mary Lou and Francesca. Also by a daughter, Nicolette, from his first marriage to Elizabeth Jones, who predeceased him.

\section{References}

1. E. C. Zeeman. Unknotting spheres in five dimensions, Bull. Amer. Math. Soc. 66 (1960) p. 198.

2. E. C. Zeeman. The generalised Poincare conjecture, Bull. Amer. Math. Soc. 6 (1961) pp. 117-119.

3. J. R. Stallings. Polyhedral homotopy-spheres, Bull. Amer. Math. Soc. 66 (1960) pp. 485-488. 
4. All twenty issues of Manifold are available free at http://ianstewartjoat.weebly.com/manifold-magazine.html

5. E. C. Zeeman. Catastrophe Theory: Selected Papers 1972-1977, Addison-Wesley, London (1977).

6. V. M. Lauschke, C. D. Tsiairis, P. François, and A. Aulehla. Scaling of embryonic patterning based on phase-gradient encoding, Nature 493 (2013) pp. 101-105.

7. I. Stewart and T. Poston. Catastrophe Theory and Its Applications, Surveys and reference works in Math. 2, Pitman, London 1978; reprint, Dover Publications, New York (1996).

8. E. C. Zeeman, On the relation between real Euclidean and complex projective geometry, Math. Gaz. 45 (May 1961) pp. 108-117.

9. E. C. Zeeman, Three-dimsional theorems for schools, The Mathematical Association (2005).

10.1017/mag.2016.68

IAN STEWART, FRS

Mathematics Institute, Zeeman Building, University of Warwick CV4 7AL 